\title{
Sulfur/Gadolinium-Codoped $\mathrm{TiO}_{2}$ Nanoparticles for Enhanced Visible-Light Photocatalytic Performance
}

\author{
Eric S. Agorku, ${ }^{1}$ Bhekie B. Mamba, ${ }^{1}$ Avinash C. Pandey, ${ }^{2}$ and Ajay K. Mishra ${ }^{1}$ \\ ${ }^{1}$ Department of Applied Chemistry, University of Johannesburg, P.O. Box 17011, Doornfontein Campus, \\ Johannesburg 2028, South Africa \\ ${ }^{2}$ Nanotechnology and Application Centre, University of Allahabad, Allahabad 211002, India \\ Correspondence should be addressed to Ajay K. Mishra; amishra@uj.ac.za
}

Received 4 October 2013; Revised 20 November 2013; Accepted 4 December 2013; Published 6 April 2014

Academic Editor: Godwin Ayoko

Copyright (C) 2014 Eric S. Agorku et al. This is an open access article distributed under the Creative Commons Attribution License, which permits unrestricted use, distribution, and reproduction in any medium, provided the original work is properly cited.

\begin{abstract}
A series of $\mathrm{S} / \mathrm{Gd}^{3+}$-codoped $\mathrm{TiO}_{2}$ photocatalysts were synthesized by a modified sol-gel method. The materials were characterized by X-ray diffraction (XRD), Raman spectroscopy, Fourier transform infrared spectroscopy (FTIR), UV-visible diffuse reflectance spectroscopy, scanning electron microscopy (SEM)/energy-dispersive X-ray spectroscopy (EDX), and transmission electron microscopy (TEM)/energy-dispersive spectroscopy (EDS). Laboratory experiments with Indigo Carmine chosen as a model for organic pollutants were used to evaluate the photocatalytic performance of $\mathrm{S} / \mathrm{Gd}^{3+}$-codoped $\mathrm{TiO}_{2}$ under visible-light with varying concentrations of $\mathrm{Gd}^{3+}$ ions in the host material. XRD and Raman results confirmed the existence of anatase phase $\mathrm{TiO}_{2}$ with particle size ranging from 5 to $12 \mathrm{~nm}$. Codoping has exerted a great influence on the optical responses along with red shift in the absorption edge. $\mathrm{S} / \mathrm{Gd}^{3+}$-codoped $\mathrm{TiO}_{2}$ showed significant visible-light induced photocatalytic activity towards Indigo Carmine dye compared with $\mathrm{S}-\mathrm{TiO}_{2}$ or commercial $\mathrm{TiO}_{2} . \mathrm{TiO}_{2}-\mathrm{S} / \mathrm{Gd}^{3+}\left(0.6 \% \mathrm{Gd}^{3+}\right)$ degraded the dye $\left(k_{a}=5.6 \times 10^{-2} \mathrm{~min}^{-1}\right)$ completely in $50 \mathrm{~min}$.
\end{abstract}

\section{Introduction}

Recent advances in nanotechnology have shown significant interest in the study of semiconductor nanocrystals owing to their unique electronic and optical properties due to quantum confinement effect [1-5]. Semiconductors have attracted much attention in the past few decades due to their unique photocatalytic, magnetic, and optical properties. They have been widely used in solar energy applications, such as photovoltaic, photochemical, and photocatalytic remediation $[6,7]$. Photocatalytic activities of semiconducting inorganic solids have attracted passionate research interest in the past few years, where their potential use as catalysts for photodegradation of toxic organic pollutants in water has been fully or partially investigated [8-10]. Semiconductors (such as $\mathrm{TiO}_{2}, \mathrm{ZnO}, \mathrm{Fe}_{2} \mathrm{O}_{3}, \mathrm{CdS}$, and $\mathrm{ZnS}$ ), which are characterized by filled valence band and empty conduction band [11], are proved to be important materials due to the electronic structure of the metal atom in chemical combination.
Nowadays scientific and engineering interest in $\mathrm{TiO}_{2}$ semiconductor have received much attention owing to its high photocatalytic activity, strong oxidizing power, low cost, chemical and thermal stability, resistance to photocorrosion and nontoxicity, and its favorable optoelectronic property [12]. However, the wide band gap (anatase: $3.2 \mathrm{eV}$, rutile: $3.0 \mathrm{eV}$ ) limits its photocatalytic efficiency. Even though the anatase is known to be the most reactive phase of $\mathrm{TiO}_{2}$ than the rutile crystalline phase, it has low quantum yield for oxidation steps $(\sim 5 \%)$ as a result of rapid recombination of photogenerated electron-hole pairs [13]. The high intrinsic band gap of pure $\mathrm{TiO}_{2}$ operates effectively as a photocatalyst in the UV region of the electromagnetic spectrum. Thus, pure $\mathrm{TiO}_{2}$ is able to use only around $4 \%$ of terrestrial solar spectrum because of its wide band gap [14]. In order to harness the full potential of the sunlight in photocatalysis, various methods, such as sensitization $[15,16]$, composite semiconductor coupling $[17,18]$, and doping of $\mathrm{TiO}_{2}[19,20]$, have been developed to overcome this challenge. 
Nonmetal doping as an alternative for improving the visible light response of $\mathrm{TiO}_{2}$ has been employed [21-23], and extensive research work has been done on synthesis of $\mathrm{N}$ doped, C-doped, S-doped, and F-doped $\mathrm{TiO}_{2}$ [24-27]. The doping of nonmetal could narrow the band gap by modifying the electronic structure around the conduction band of $\mathrm{TiO}_{2}$. Theoretical calculation has shown that band gap narrowing originates from the electronic perturbations caused by the change of lattice parameters and/or by the presence of the trapped states within conduction and valence bands of $\mathrm{TiO}_{2}$ [28-34].

Many of the recent efforts and strategies revealed that codoping of $\mathrm{TiO}_{2}$ with a metal and nonmetal can result in the development of a highly efficient visible light active photocatalyst [35-37]. A series of studies reported the characteristic behavior of visible-active metal-doped semiconductor photocatalysts, including noble metals [38], rare earth metals [39], and transition metals [40]. Several rare earth metal ions such as $\mathrm{La}^{3+}, \mathrm{Eu}^{3+}, \mathrm{Nd}^{3+}$, and $\mathrm{Ce}^{3+}$, when doped in $\mathrm{TiO}_{2}$, showed considerable shift of absorption towards visible region [41-44]. Additionally, lanthanide ions have the aptitude to form complexes with a variety of organic pollutants by the interaction of functional groups with $f$ orbitals of the lanthanides. This could provide a way to concentrate organic pollutants at the semiconductor surface [45].

Intrigued by these observations, we synthesized highly efficient visible light active $\mathrm{S} / \mathrm{Gd}^{3+}$-codoped $\mathrm{TiO}_{2}$ nanoparticles by modified sol-gel method. The preparation of $\mathrm{S} / \mathrm{Gd}^{3+}$ codoped $\mathrm{TiO}_{2}$ was optimized by varying the amount of $\mathrm{Gd}^{3+}$ to obtain an effective photocatalyst. The catalysts exhibited a higher visible light photocatalytic activity towards the degradation of Indigo Carmine (IC) in aqueous solution.

\section{Experimental Details}

All chemicals used were of analytical grade and used without further treatment. Titanium (IV) isopropoxide, $\mathrm{Ti}\left(\mathrm{OC}_{3} \mathrm{H}_{7}\right)_{4}$ (97\%), Indigo Carmine, gadolinium (III) nitrate hexahydrate $\left(\mathrm{Gd}\left(\mathrm{NO}_{3}\right)_{3} \cdot 6 \mathrm{H}_{2} \mathrm{O}\right)$, titanium (IV) oxide (product number $634662,99.5 \%,<100 \mathrm{~nm})$, and 2-propanol, $\mathrm{C}_{3} \mathrm{H}_{8} \mathrm{O}(99.8 \%)$ were purchased from Sigma Aldrich, Germany. Thiourea, $\mathrm{CS}\left(\mathrm{NH}_{3}\right)_{2}(99 \%)$ was purchased from Hopkin and Williams Ltd., England.

2.1. Sample Preparation. $\mathrm{S} / \mathrm{Gd}^{3+}$-codoped $\mathrm{TiO}_{2}$ was prepared by adding titanium isopropoxide $(10 \mathrm{~mL})$ to 2-propanol $(50 \mathrm{~mL})$ slowly and the mixture stirred for $30 \mathrm{~min}$. A calculated amount of gadolinium (III) nitrate hexahydrate was dissolved in DI water $(2 \mathrm{~mL})$ and added to the mixture to give Gd: Ti of $0.2-1.0 \%$ and the mixture was further stirred for $1 \mathrm{~h}$. Then thiourea $(3.0 \mathrm{~g})$, dissolved in DI water $(5 \mathrm{~mL})$, was added slowly with vigorous stirring for $2 \mathrm{~h}$. The resulting mixture was dried in air in an oven at $100^{\circ} \mathrm{C}$ for $12 \mathrm{~h}$ and calcined at $500^{\circ} \mathrm{C}$ for $2 \mathrm{~h}$. $\mathrm{TiO}_{2}-\mathrm{S} / \mathrm{Gd}^{3+}\left(0.0 \% \mathrm{Gd}^{3+}\right)$ sample was prepared in a similar manner without gadolinium (III) nitrate hexahydrate.
2.2. Evaluation of Photocatalytic Activity. The photocatalytic activity of the materials was evaluated through a suspension of $100 \mathrm{mg}$ of the catalyst in $100 \mathrm{~mL}$ of aqueous solution of Indigo Carmine $(20 \mathrm{mg} / \mathrm{L})$ that was kept under magnetic stirring and visible light irradiation filtered using dichroic UV filter $(\lambda>420 \mathrm{~nm})$. A $150 \mathrm{~W}$ tungsten filament (Eurolux), kept at a distance of $11 \mathrm{~cm}$ from the reaction vessel, was employed as a source of radiation. The samples were magnetically stirred in the dark for $1 \mathrm{~h}$ prior to illumination to allow for adsorption equilibrium. Aliquots of the suspension $(5 \mathrm{~mL})$ were withdrawn at periodic time intervals using disposable syringe and filtered through $0.4 \mu \mathrm{m}$ PVDF membrane filter at $30 \mathrm{~min}$ intervals for $4 \mathrm{hrs}$. The concentration of the Indigo Carmine remaining after illumination in the supernatant solution was determined using a Shimadzu UV2450 spectrophotometer at $\lambda=610 \mathrm{~nm}$. The photodegradation performance of the process was assessed in terms of decolorization efficiencies and kinetic studies.

2.3. Characterization. X-ray diffraction (XRD) measurements were performed on X-ray diffractometer (Rigaku Ultima IV) at $40 \mathrm{kV}$ and $30 \mathrm{~mA}$ with $\mathrm{Cu} \mathrm{K} \alpha$ radiation $(\lambda=$ 0.15406 ) and K-beta filter. Measurements were performed using a scintillation counter in the range of 5-90 deg at a speed of $2.0 \mathrm{deg} / \mathrm{min}$. FT-IR spectra of the samples were recorded on PerkinElmer FT-IR spectrometer (Spectrum 100). Raman spectra of the samples were measured on PerkinElmer Raman microscope (Raman Micro 200). Optical properties were investigated using UV-vis absorption and UV-vis diffuse reflectance spectroscopy on a Shimadzu UV2540 (Japan). $\mathrm{BaSO}_{4}$ was used as the reflectance standard. Scanning electron microscopy (SEM) studies were obtained on a TESCAN (Vega $3 \mathrm{XMU}$ ) to observe the surface morphology of the powders and high resolution transmission electron spectroscopy (HRTEM) analysis was performed on a JEOL field emission electron microscope (JEM-2100F) to observe the surface morphology, structure, and grain size of the nanoparticles. Energy-dispersive X-ray spectroscopy (EDX) attached to the SEM and energy-dispersive spectroscopy (EDS) attached to HRTEM were used to determine the surface elemental composition.

\section{Results and Discussions}

3.1. FT-IR Analysis. The FT-IR spectra provide information on the surface chemistry of the oxide nanoparticles which are usually affected by the hydration layers or organic species which are characterized by several bands as demonstrated by several studies. Figure 1 shows the FT-IR spectra of $\mathrm{S}-\mathrm{TiO}_{2}$ and $\mathrm{S} / \mathrm{Gd}^{3+}$-codoped $\mathrm{TiO}_{2}$ with different $\mathrm{Gd}^{3+}$ concentrations calcined at $500^{\circ} \mathrm{C}$. The most common feature observed in all the spectra is the appearance of (i) broad bands below $1000 \mathrm{~cm}^{-1}$ assignable to the $\mathrm{Ti}-\mathrm{O}-\mathrm{Ti}$ crystal vibration [46] and (ii) those in the regions between $1620-1635 \mathrm{~cm}^{-1}$ and $3350-3450 \mathrm{~cm}^{-1}$ both due to bending vibrations of adsorbed water molecules and stretching vibrations [47] from the hydroxyl groups, respectively. The $\mathrm{Ti}-\mathrm{S}$ peaks are the broad intense peaks below $1000 \mathrm{~cm}^{-1}$ [48]. The peak at around 


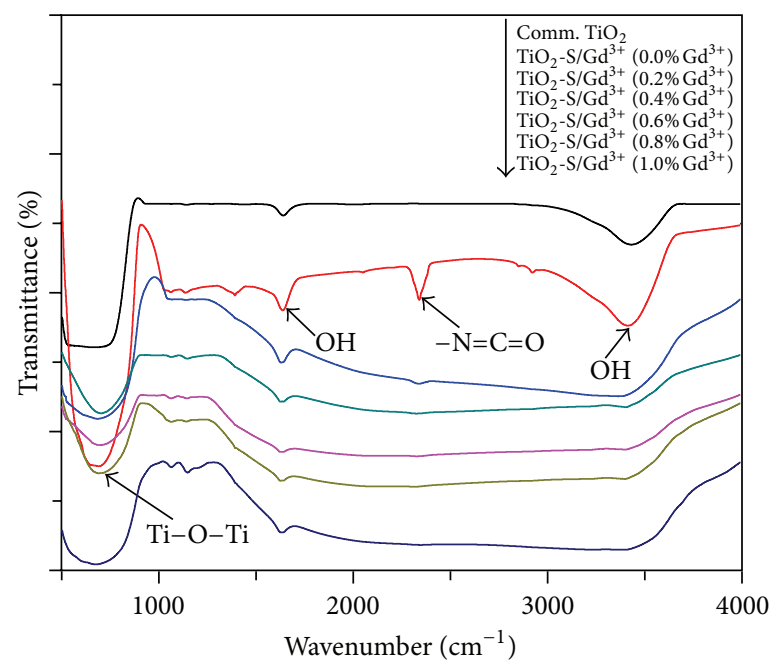

FIGURE 1: FT-IR spectra of $\mathrm{S} / \mathrm{Gd}^{3+}$-codoped $\mathrm{TiO}_{2}$ with different concentrations of $\mathrm{Gd}^{3+}$.

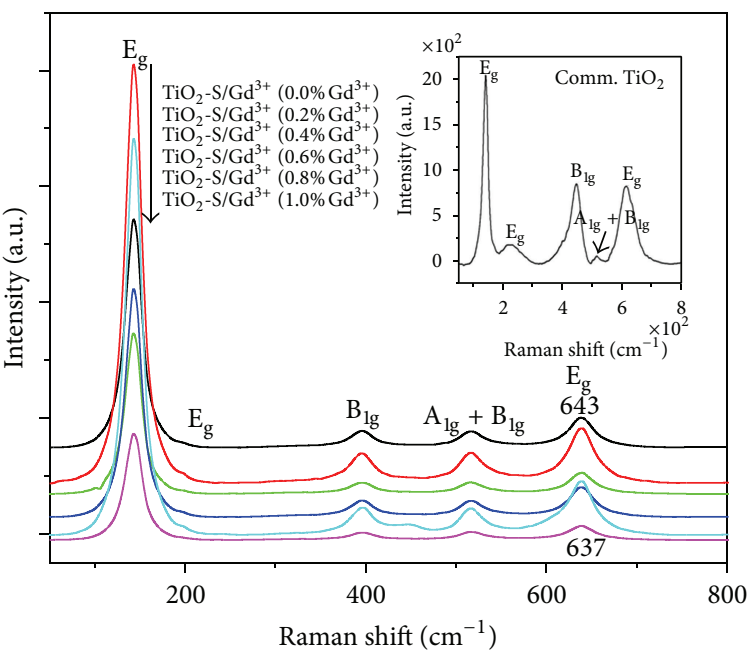

Figure 2: Raman spectra of $\mathrm{S} / \mathrm{Gd}^{3+}$-codoped $\mathrm{TiO}_{2}$ with different concentrations of $\mathrm{Gd}^{3+}$. Insert: Raman spectrum of commercial $\mathrm{TiO}_{2}$.

$2340 \mathrm{~cm}^{-1}$, which is dominant for the S-doped sample but absent in the commercial $\mathrm{TiO}_{2}$, may be due to out-of-phase stretching of the $-\mathrm{N}=\mathrm{C}=\mathrm{O}$ bond [49], which was left behind on the surface by incomplete decomposition of thiourea [50]. The shift to the larger wavenumbers (from $\sim 665$ to $\sim 722 \mathrm{~cm}^{-1}$ ) and the sharpening of the Ti-O-Ti bands may be due to gadolinium doping. There is, however, no peak centered at $1389 \mathrm{~cm}^{-1}$ which is due to the bending vibrations of $\mathrm{C}-\mathrm{H}$ bond in the catalyst [51] and no residual alkoxy peaks were observed indicating the absence of impurities in the samples after calcinations.

3.2. Raman Spectroscopic Analysis. Raman spectroscopy provides additional information about the anatase crystallinity. Factor group analysis shows six Raman active modes $\left(\mathrm{A}_{1 \mathrm{~g}}+\right.$ $2 \mathrm{~B}_{1 \mathrm{~g}}+3 \mathrm{E}_{\mathrm{g}}$ ) for anatase $\mathrm{TiO}_{2}$ [52]. In this study, pronounced vibrational modes were observed for all the samples as shown in Figure 2. All the Raman spectra measured confirmed anatase phase of $\mathrm{TiO}_{2}$. The Raman modes can be assigned to the Raman spectra of the anatase crystal. ${ }^{49}: \sim 143\left(\mathrm{E}_{\mathrm{g}}\right)$, $197\left(\mathrm{E}_{\mathrm{g}}\right), 398\left(\mathrm{~B}_{1 \mathrm{~g}}\right), 515\left(\mathrm{~A}_{1 \mathrm{~g}}+\mathrm{B}_{1 \mathrm{~g}}\right)$, and $639 \mathrm{~cm}^{-1}\left(\mathrm{E}_{\mathrm{g}}\right)$. Almost all the peaks match quite well with those reported in the literature, confirming the formation of pure anatase phase. However, herein, only five pronounced bands appear probably due to overlapping of $\mathrm{A}_{1 \mathrm{~g}}$ and $\mathrm{B}_{1 \mathrm{~g}}$ bands. At the same time, the blue or red shift, accompanied with some bands, may be explained in terms of reduction in crystallite sizes in the doped $\mathrm{TiO}_{2}$ samples as noted earlier by others [53]. It is worth noting that reduction in the crystallite sizes has also been confirmed by the XRD measurements mentioned below. The highly intense $\mathrm{E}_{\mathrm{g}}$ mode is due to scattering from the (110) face and $B_{1 g}$ mode from the (001). There was a shift in the position of the anatase $\mathrm{E}_{\mathrm{g}}$ mode as a result of gadolinium doping from $637 \mathrm{~cm}^{-1}$ to $643 \mathrm{~cm}^{-1}$ for gadolinium-doped and -undoped $\mathrm{S}_{-} \mathrm{TiO}_{2}$, respectively. This shift may be ascribed to $\mathrm{Gd}_{2} \mathrm{O}_{3} \mathrm{E}_{\mathrm{g}}$ mode in the samples. There was no intense 


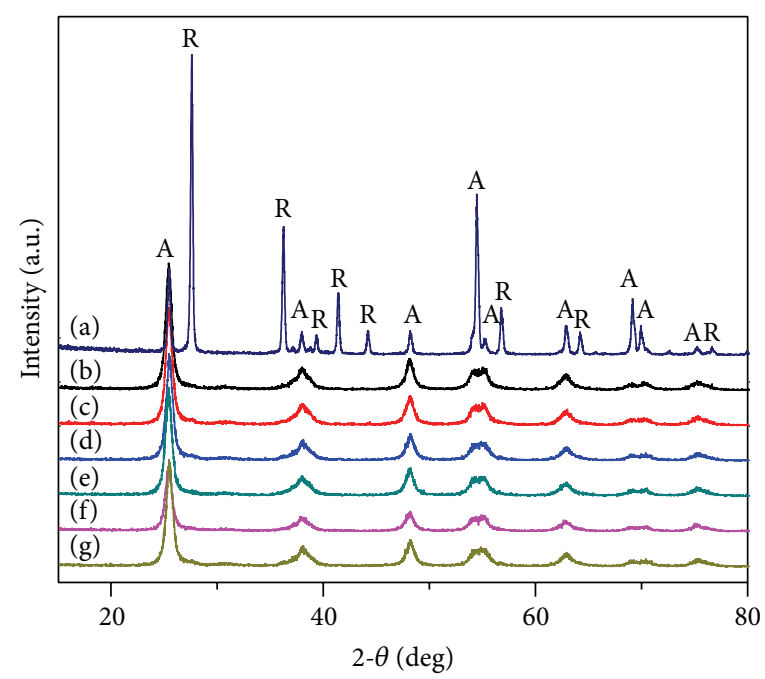
(a) Comm. $\mathrm{TiO}_{2}$
(e) $\mathrm{TiO}_{2}-\mathrm{S} / \mathrm{Gd}^{3+}\left(0.6 \% \mathrm{Gd}^{3+}\right)$
(b) $\mathrm{TiO}_{2}-\mathrm{S} / \mathrm{Gd}^{3+}\left(0.0 \% \mathrm{Gd}^{3+}\right)$
(c) $\mathrm{TiO}_{2}-\mathrm{S} / \mathrm{Gd}^{3+}\left(0.2 \% \mathrm{Gd}^{3+}\right)$
(f) $\mathrm{TiO}_{2}-\mathrm{S} / \mathrm{Gd}^{3+}\left(0.8 \% \mathrm{Gd}^{3+}\right)$
(d) $\mathrm{TiO}_{2}-\mathrm{S} / \mathrm{Gd}^{3+}\left(0.4 \% \mathrm{Gd}^{3+}\right)$
(g) $\mathrm{TiO}_{2}-\mathrm{S} / \mathrm{Gd}^{3+}\left(1.0 \% \mathrm{Gd}^{3+}\right)$

FIGURE 3: XRD pattern of $\mathrm{S} / \mathrm{Gd}^{3+}$-codoped $\mathrm{TiO}_{2}$ with different concentrations of $\mathrm{Gd}^{3+}$.

Raman band at $\sim 333 \mathrm{~cm}^{-1}$ which is as a result of $\mathrm{A}_{1 \mathrm{~g}}+\mathrm{F}_{\mathrm{g}}$ symmetry vibration of the cubic $\mathrm{Gd}_{2} \mathrm{O}_{3}$ indicating the partial replacement of $\mathrm{Ti}$ by $\mathrm{Gd}$ in the $\mathrm{TiO}_{2}$ crystal lattice. The sharp, narrow intense peaks show crystalline state and the crystallinity was not changed as a result of doping.

3.3. X-Ray Diffraction Study. The size and the crystalline phase formation were investigated by $\mathrm{X}$-ray diffraction. The XRD measurements for $\mathrm{S}-\mathrm{TiO}_{2}$ and $\mathrm{S} / \mathrm{Gd}^{3+}$-codoped $\mathrm{TiO}_{2}$ are shown in Figure 3. All the samples show anatase phase. The diffraction patterns of the anatase $\mathrm{S} / \mathrm{Gd}^{3+}$-codoped $\mathrm{TiO}_{2}$ and $\mathrm{S}-\mathrm{TiO}_{2}$ powders were compared with JCPDS database. The peak positions and their relative intensities are consistent with the standard powder diffraction pattern of anatase $\mathrm{TiO}_{2}$. XRD patterns (Figure 3 ) exhibited strong diffraction peaks at $25^{\circ}$ and $48^{\circ}$, indicating $\mathrm{TiO}_{2}$ in the anatase phase. All the peaks are in good agreement with the standard spectrum (JCPDS number 84-1286). The peaks at $2 \theta$ values of 25.3, 37.8, $48.1,54.0,55.1,62.9$, and 75.2 correspond to the (101), (004), (200), (105), (211), (204), and (215) planes, respectively. All these peaks depict the anatase signature peaks. The sharp, intense anatase peaks show an improvement in the degree of crystallinity with fewer lattice defects. The XRD patterns show that there was no second-phase peak and also that the doping was successful. Also, in $\mathrm{S}-\mathrm{TiO}_{2}$ system, the $\mathrm{S}$ atoms may be attributed to be replaced some of the oxygen atoms in the $\mathrm{TiO}_{2}$ crystal lattice. The absence of any residual peak(s) explains the fact that there is no sulphur found on the surface of the nanocrystal. From the XRD results it can be concluded that sulphur is in a high dissolution state in the $\mathrm{TiO}_{2}$ lattice rather than an isolated species on the surface of $\mathrm{TiO}_{2}$. The presence of sulphur and gadolinium was, however, confirmed by elemental analysis using EDS and EDX.
The average crystalline size was estimated from Scherrer's equation on the anatase $\left(2 \theta=25.3,37.8\right.$, and $\left.48.1^{\circ}\right)$ diffraction peaks (the most intense peaks for each sample):

$$
D=\frac{K \lambda}{\beta \operatorname{Cos} \theta},
$$

where $D$ is the crystal size of the catalyst, $\lambda$ is the $\mathrm{X}$-ray wavelength (1.54056 $\AA$ ), $\beta$ is the full width at maximum (FWHM) of the diffraction peak (radian), $K$ is a constant (0.9), and $\theta$ is the diffraction angle at the maximum [54]. The average crystalline size of $\mathrm{S}-\mathrm{Ti}_{x} \mathrm{O}_{2}-\mathrm{Gd}_{1-x}(x=0.2,0.4,0.6$, 0.8 , and 1.0) was calculated to be between 5 and $12 \mathrm{~nm}$.

3.4. TEM and SEM Study. HRTEM and SEM were used to observe the uniformity, morphology, and microstructure of the as-prepared $\mathrm{S}-\mathrm{TiO}_{2}$ and $\mathrm{S} / \mathrm{Gd}^{3+}$-codoped $\mathrm{TiO}_{2}$ nanoparticles calcined at $500^{\circ} \mathrm{C}$. Figures $4(\mathrm{a})$ and 4 (b) show a typical HRTEM and SEM image of the prepared $\mathrm{TiO}_{2}-\mathrm{S} / \mathrm{Gd}^{3+}(0.6 \%$ $\mathrm{Gd}^{3+}$ ) photocatalysts, respectively. The particles are small and nearly spherical in shape. All the samples prepared show regular morphology, regardless of $\mathrm{S} / \mathrm{Gd}$ ratio. The uniform morphology, with uniform size $(5-12 \mathrm{~nm})$, is due to improvement in the sol-gel process which resulted in the mobilization of $\mathrm{Ti}$ and $\mathrm{O}$ homogeneity in the $\mathrm{TiO}_{2}$ crystalline structure.

The elemental composition of the prepared samples was estimated by EDX and EDS analyses. Figures 5(a) and 5(b) show the EDX and EDS spectra of $\mathrm{TiO}_{2}-\mathrm{S} / \mathrm{Gd}^{3+}\left(0.6 \% \mathrm{Gd}^{3+}\right)$, respectively. Both spectra of the codoped $\mathrm{TiO}_{2}$ confirm the presence of $\mathrm{Ti}, \mathrm{Gd}, \mathrm{O}$, and $\mathrm{S}$. The spectra indicate that the main components are $\mathrm{Ti}$ and $\mathrm{O}$ with low contents of $\mathrm{Gd}$ and $\mathrm{S}$. This may be due to the formation of $\mathrm{S} / \mathrm{Gd}^{3+}$-codoped $\mathrm{TiO}_{2}$. 


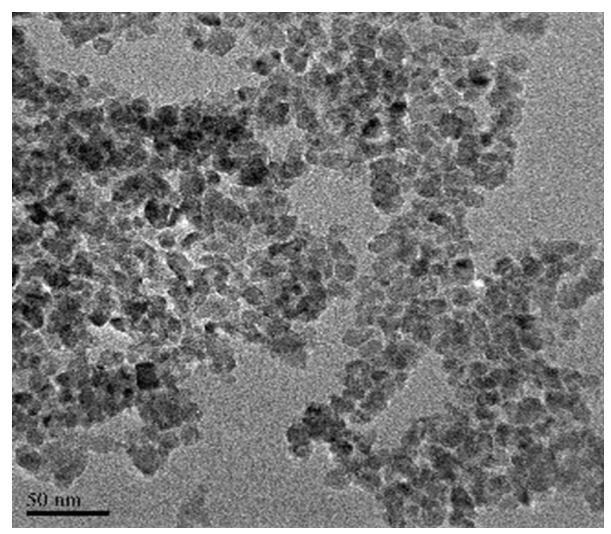

(a)

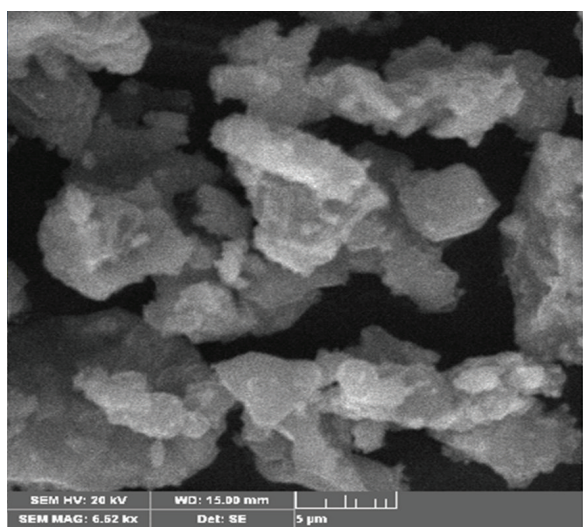

(b)

Figure 4: HRTEM image (a) and SEM image (b) of $\mathrm{S} / \mathrm{Gd}^{3+}$-codoped $\mathrm{TiO}_{2}\left(0.6 \% \mathrm{Gd}^{3+}\right)$ nanoparticles.

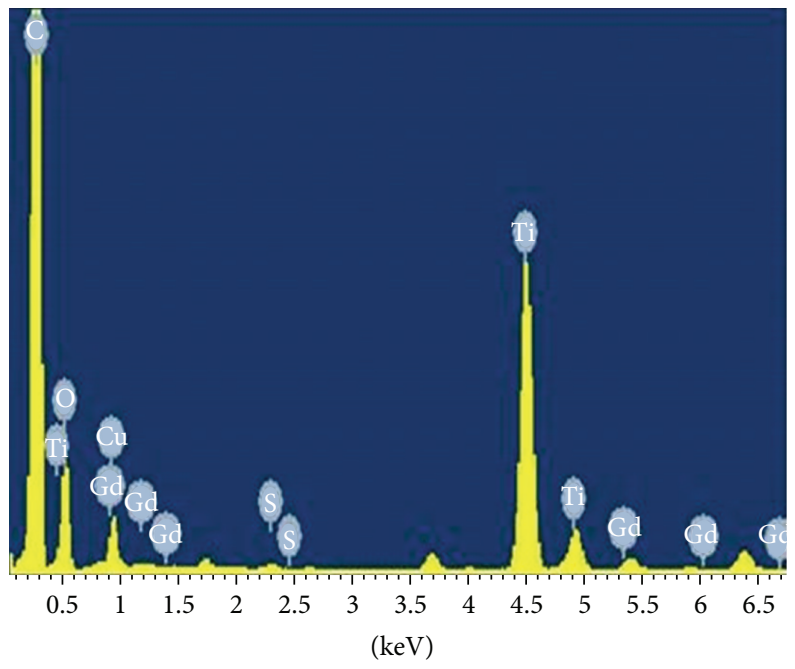

(a)

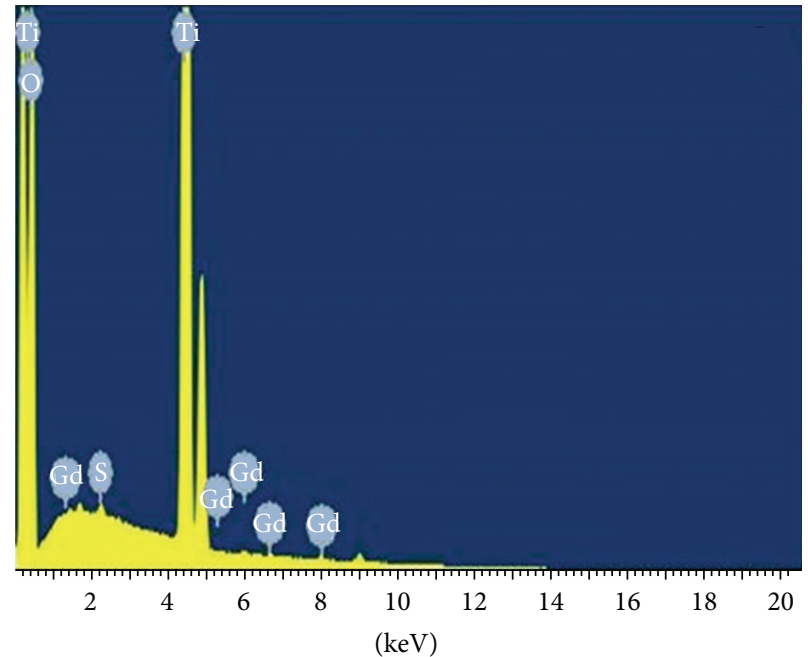

(b)

FIgURE 5: EDS spectrum (a) and EDX spectrum (b) of S/Gd $\mathrm{Gd}^{3+}$-codoped $\mathrm{TiO}_{2}\left(0.6 \% \mathrm{Gd}^{3+}\right)$ nanoparticles.

3.5. UV-Visible Study. The light absorption characteristics of $\mathrm{TiO}_{2}$ usually change after doping with nonmetal doping [21-23] and metal/nonmetal codoping [35-37]. Figures 6 and 7 show a comparison of the UV-vis absorption edge and UV-vis diffuse reflectance of commercial $\mathrm{TiO}_{2}, \mathrm{~S}_{-} \mathrm{TiO}_{2}$, and $\mathrm{S} / \mathrm{Gd}^{3+}$-codoped $\mathrm{TiO}_{2}$ (with different concentrations of $\mathrm{Gd}^{3+}$ ), respectively. The absorption spectrum of $\mathrm{TiO}_{2}$ consists of a single broad intense absorption around $400 \mathrm{~nm}$ due to the charge transfer from the valence band (mainly formed by $2 p$ orbitals of the oxide anions) to the corresponding conduction band (mainly formed by $3 \mathrm{~d} \mathrm{t}_{2}$ g orbitals of $\mathrm{Ti}^{4+}$ cation [55]. The onset of the absorption edge for pure $\mathrm{TiO}_{2}$ at $\mathrm{Ca} .385 \mathrm{~nm}$ is consistent with intrinsic band gap absorption of pure $\mathrm{TiO}_{2}$. However, in comparison with the bulk $\mathrm{TiO}_{2}$, the $\mathrm{TiO}_{2}-\mathrm{S}$ (and $\mathrm{N}$ from incomplete decomposition of thiourea, shown in Figure 1) shows two prominent features: (i) the appearance of a new absorption shoulder around $390-500 \mathrm{~nm}$ and (ii) the greatly enhanced absorbance in the range of $550-750 \mathrm{~nm}$. The overall visible-light absorbance increased with $\mathrm{Gd}^{3+}$ doping. Such red shift in absorbance in the visible-light range is partly due to the yellow characteristic colour of the $\mathrm{S}-\mathrm{TiO}_{2}$ and the synergistic effect of $\mathrm{S} / \mathrm{Gd}^{3+}$ codoping. In addition, in order to obtain a synergistic effect between $\mathrm{S}-\mathrm{TiO}_{2}$ and $\mathrm{S} / \mathrm{Gd}^{3+}$ codoped $\mathrm{TiO}_{2}$, it is important to control the addition ratios of $\mathrm{Gd}$, which lead to an optimum photocatalytic activity. It was obvious that the $\mathrm{TiO}_{2}-\mathrm{S} / \mathrm{Gd}^{3+}\left(0.6 \% \mathrm{Gd}^{3+}\right)$ nanoparticles exhibited the best visible-light absorption with improved band gap.

Figure 8 shows a plot of the Kubelka-Munk function, $F(R)$, versus wavelength based on the following KubelkaMunk equation:

$$
F(R)=\frac{(1-R)^{2}}{2 R},
$$

where reflectance, $R=R_{\text {sample }} / R_{\text {reference }}$. The plot shows a significant red shift in the absorption coefficient of the 


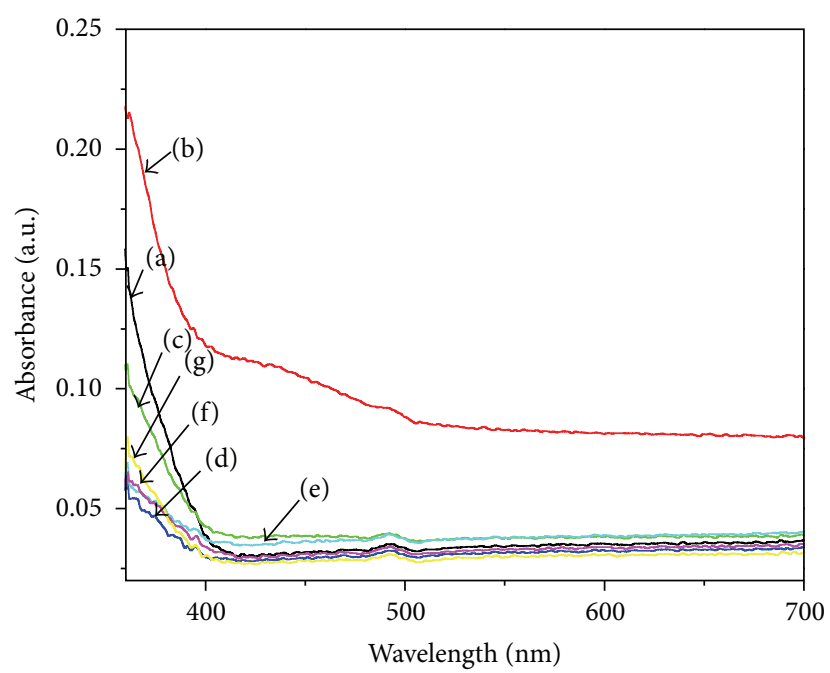
(a) $\mathrm{Comm} . \mathrm{TiO}_{2}$
(e) $\mathrm{TiO}_{2}-\mathrm{S} / \mathrm{Gd}^{3+}\left(0.6 \% \mathrm{Gd}^{3+}\right)$
(b) $\mathrm{TiO}_{2}-\mathrm{S} / \mathrm{Gd}^{3+}\left(0.0 \% \mathrm{Gd}^{3+}\right)$
(c) $\mathrm{TiO}_{2}-\mathrm{S} / \mathrm{Gd}^{3+}\left(0.2 \% \mathrm{Gd}^{3+}\right)$
(d) $\mathrm{TiO}_{2}-\mathrm{S} / \mathrm{Gd}^{3+}\left(0.4 \% \mathrm{Gd}^{3+}\right)$
(f) $\mathrm{TiO}_{2}-\mathrm{S} / \mathrm{Gd}^{3+}\left(0.8 \% \mathrm{Gd}^{3+}\right)$
(g) $\mathrm{TiO}_{2}-\mathrm{S} / \mathrm{Gd}^{3+}\left(1.0 \% \mathrm{Gd}^{3+}\right)$

FIgURE 6: UV-visible spectra of commercial and $\mathrm{S} / \mathrm{Gd}^{3+}$-codoped $\mathrm{TiO}_{2}$ with different concentrations of $\mathrm{Gd}^{3+}$.

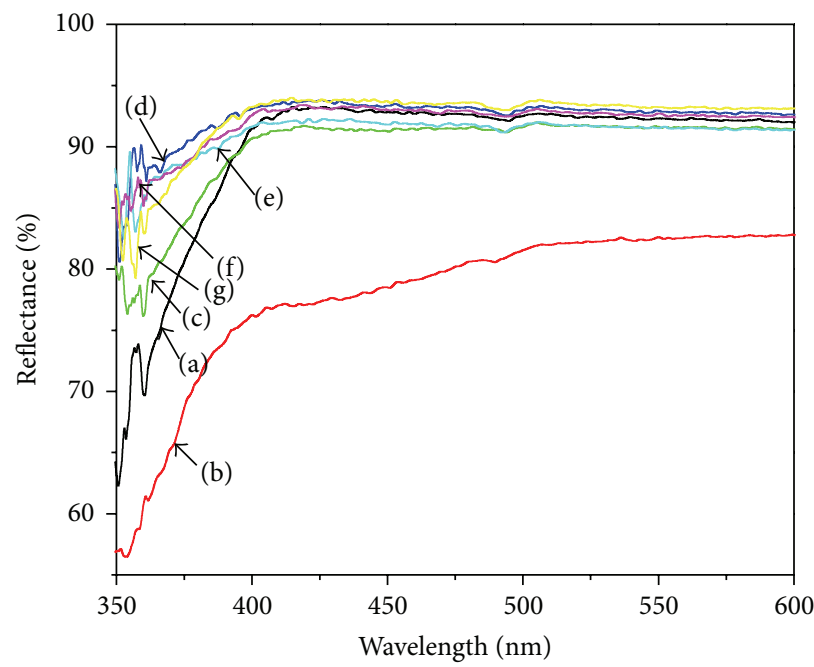
(a) Comm. $\mathrm{TiO}_{2}$
(e) $\mathrm{TiO}_{2}-\mathrm{S} / \mathrm{Gd}^{3+}\left(0.6 \% \mathrm{Gd}^{3+}\right)$
(b) $\mathrm{TiO}_{2}-\mathrm{S} / \mathrm{Gd}^{3+}\left(0.0 \% \mathrm{Gd}^{3+}\right)$
(c) $\mathrm{TiO}_{2}-\mathrm{S} / \mathrm{Gd}^{3+}\left(0.2 \% \mathrm{Gd}^{3+}\right)$
(d) $\mathrm{TiO}_{2}-\mathrm{S} / \mathrm{Gd}^{3+}\left(0.4 \% \mathrm{Gd}^{3+}\right)$
(f) $\mathrm{TiO}_{2}-\mathrm{S} \mathrm{Gd}^{3+}\left(0.8 \% \mathrm{Gd}^{3+}\right)$
(g) $\mathrm{TiO}_{2}-\mathrm{S} / \mathrm{Gd}^{3+}\left(1.0 \% \mathrm{Gd}^{3+}\right)$

FIgURE 7: Diffuse reflectance UV-visible spectra of commercial $\mathrm{TiO}_{2}$ and $\mathrm{S} / \mathrm{Gd}^{3+}$-codoped $\mathrm{TiO}_{2}$ with different concentrations of $\mathrm{Gd}{ }^{3+}$.

$\mathrm{S} / \mathrm{Gd}^{3+}$-codoped photocatalyst. Figure 9 contains Tauc [56] plots constructed from the Kubelka-Munk data (obtained from the UV-visible diffuse reflectance) for the photocatalysts as well as for the commercial benchmark sample. The band gap energies for the various samples were calculated by plotting the values of $(F(R) * h \nu)^{n}$ versus the photon energy $(h \nu)$. The band gap values are estimated from a plot of $[F(R) \cdot h \nu]^{n}$ versus $h v$. The indirect band gap values are summarized in Table 1 . The number $n$ depends on the nature of the electronic transition and is 1 for a direct and $1 / 2$ for an indirect band gap for semiconductors with a crystalline structure [56].

Extrapolation of this line to the photon energy axis (Figure 9) gives the semiconductor band gap, which is a key indicator of its visible light efficiency. Commercial $\mathrm{TiO}_{2}$ also shows an absorption edge that fits well to the energy axis. Comparing the band gap of commercial $\mathrm{TiO}_{2}$ and the $\mathrm{S} / \mathrm{Gd}^{3+}$-codoped samples, the latter shows significant reduction in the band gap with gadolinium doping. The increase in the band gap with gadolinium doping may be 


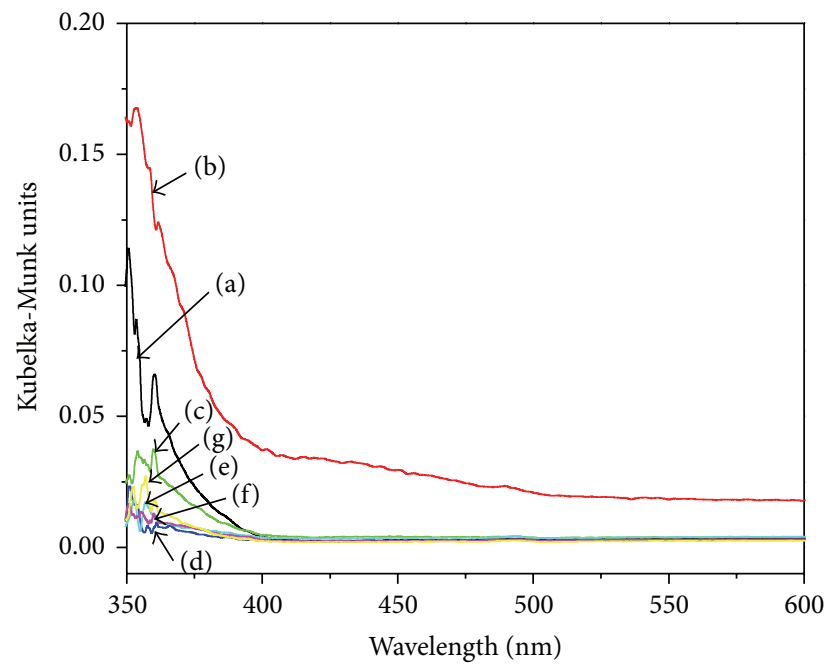
(a) $\mathrm{Comm} . \mathrm{TiO}_{2}$
(e) $\mathrm{TiO}_{2}-\mathrm{S} / \mathrm{Gd}^{3+}\left(0.6 \% \mathrm{Gd}^{3+}\right)$
(b) $\mathrm{TiO}_{2}-\mathrm{S} / \mathrm{Gd}^{3+}\left(0.0 \% \mathrm{Gd}^{3+}\right)$
(c) $\mathrm{TiO}_{2}-\mathrm{S} / \mathrm{Gd}^{3+}\left(0.2 \% \mathrm{Gd}^{3+}\right)$
(f) $\mathrm{TiO}_{2}-\mathrm{S} / \mathrm{Gd}^{3+}\left(0.8 \% \mathrm{Gd}^{3+}\right)$
(d) $\mathrm{TiO}_{2}-\mathrm{S} / \mathrm{Gd}^{3+}\left(0.4 \% \mathrm{Gd}^{3+}\right)$
(g) $\mathrm{TiO}_{2}-\mathrm{S} / \mathrm{Gd}^{3+}\left(1.0 \% \mathrm{Gd}^{3+}\right)$

FIgURE 8: Kubelka-Munk plots for commercial $\mathrm{TiO}_{2} \mathrm{~S} / \mathrm{Gd}^{3+}$-codoped $\mathrm{TiO}_{2}$ with different concentrations of $\mathrm{Gd}^{3+}$.

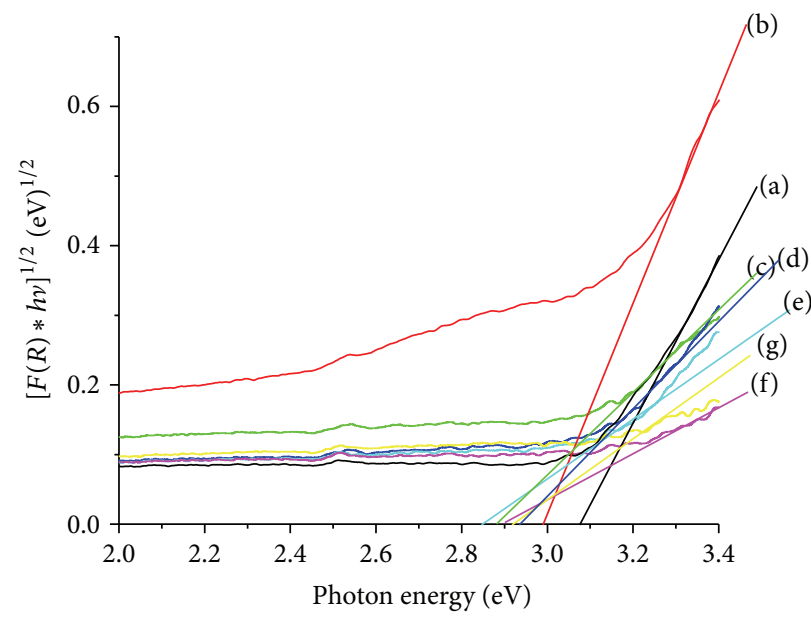
(a) Comm. $\mathrm{TiO}_{2}$
(e) $\mathrm{TiO}_{2}-\mathrm{S} / \mathrm{Gd}^{3+}\left(0.6 \% \mathrm{Gd}^{3+}\right)$

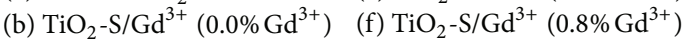
$\begin{array}{ll}\text { (c) } \mathrm{TiO}_{2}-\mathrm{S} / \mathrm{Gd}^{3+}\left(0.2 \% \mathrm{Gd}^{3+}\right) & (\mathrm{g}) \mathrm{TiO}_{2}-\mathrm{S} / \mathrm{Gd}^{3+}\left(1.0 \% \mathrm{Gd}^{3+}\right)\end{array}$
(d) $\mathrm{TiO}_{2}-\mathrm{S} / \mathrm{Gd}^{3+}\left(0.4 \% \mathrm{Gd}^{3+}\right)$

FIgUre 9: Tauc plots for commercial $\mathrm{TiO}_{2}$ and $\mathrm{S} / \mathrm{Gd}^{3+}$-codoped $\mathrm{TiO}_{2}$ with different concentrations of $\mathrm{Gd}^{3+}$.

TABLE 1: Indirect band gap and percentage degradation after exposure to visible-light radiation.

\begin{tabular}{lccr}
\hline Sample & Indirect band gap $(\mathrm{eV})$ & ${\text { Degradation }(\%)^{\mathrm{a}}}^{\mathrm{a}}$ & $k\left(\mathrm{~min}^{-1}\right)^{\mathrm{b}}$ \\
\hline $\mathrm{Commerrcial} \mathrm{TiO}_{2}$ & 3.08 & 34.8 & $6.5 \times 10^{-3} \pm 0.0004$ \\
$\mathrm{TiO}_{2}-\mathrm{S} / \mathrm{Gd}^{3+}\left(0.0 \% \mathrm{Gd}^{3+}\right)$ & 3.04 & 56.6 & $1.7 \times 10^{-2} \pm 0.0019$ \\
$\mathrm{TiO}_{2}-\mathrm{S} / \mathrm{Gd}^{3+}\left(0.2 \% \mathrm{Gd}^{3+}\right)$ & 2.90 & 88.1 & $4.8 \times 10^{-2} \pm 0.0031$ \\
$\mathrm{TiO}_{2}-\mathrm{S} / \mathrm{Gd}^{3+}\left(0.4 \% \mathrm{Gd}^{3+}\right)$ & 2.86 & 92.6 & $4.1 \times 10^{-2} \pm 0.0105$ \\
$\mathrm{TiO}_{2}-\mathrm{S} / \mathrm{Gd}^{3+}\left(0.6 \% \mathrm{Gd}^{3+}\right)$ & 2.63 & 100.0 & $5.6 \times 10^{-2} \pm 0.0092$ \\
$\mathrm{TiO}_{2}-\mathrm{S} / \mathrm{Gd}^{3+}\left(0.8 \% \mathrm{Gd}^{3+}\right)$ & 2.75 & 67.7 & $6.4 \times 10^{-2} \pm 0.0131$ \\
$\mathrm{TiO}_{2}-\mathrm{S} / \mathrm{Gd}^{3+}\left(1.0 \% \mathrm{Gd}^{3+}\right)$ & 2.95 & 70.1 & $1.9 \times 10^{-2} \pm 0.0017$ \\
\hline
\end{tabular}

${ }^{\mathrm{a}}$ Measured after reaction for $50 \mathrm{~min} .{ }^{\mathrm{b}}$ Apparent rate constant calculated from the linear fitting of $\ln \left(C_{0} / C\right)$ versus reaction time after $40 \mathrm{~min}$. 


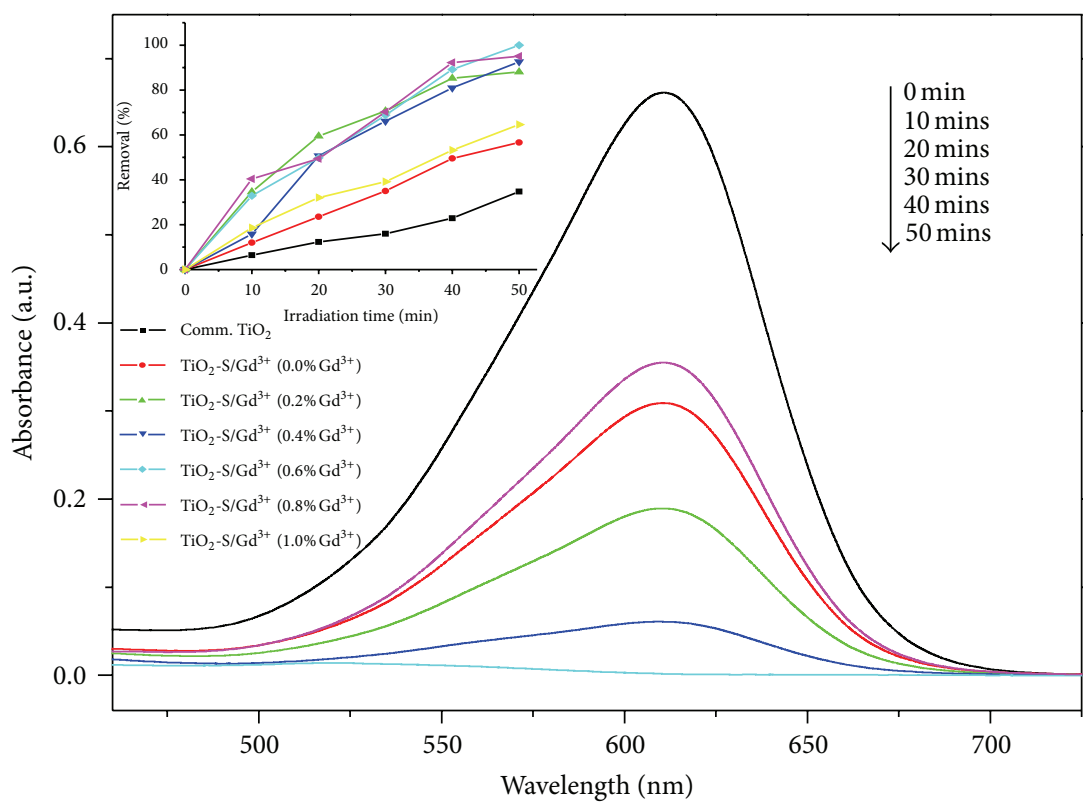

FIGURE 10: Indigo Carmine photodegradation profile using $\mathrm{TiO}_{2}-\mathrm{S} / \mathrm{Gd}^{3+}\left(0.6 \% \mathrm{Gd}^{3+}\right)$.

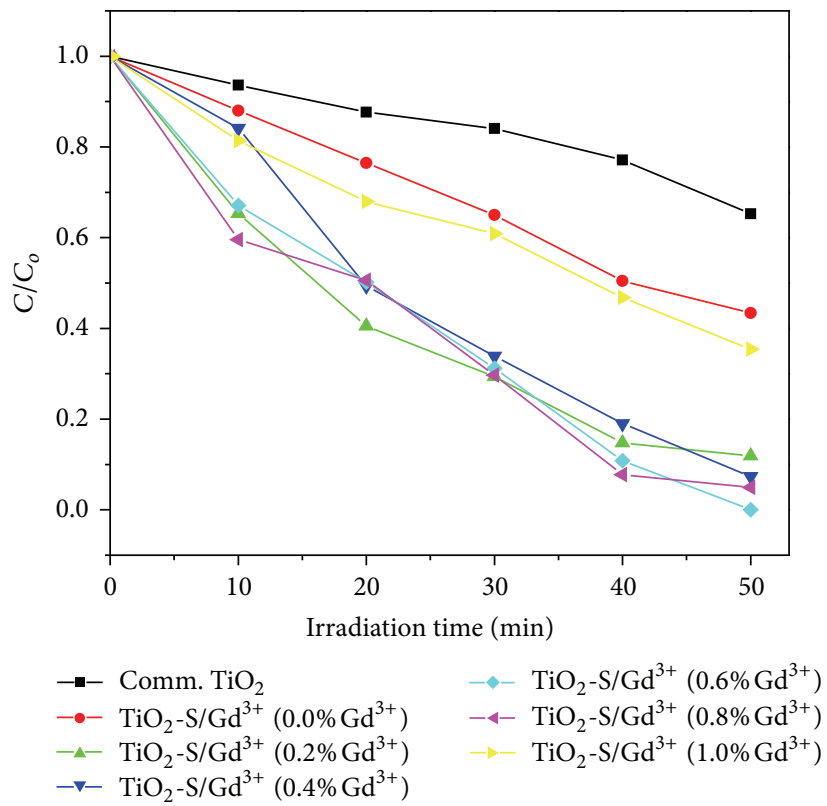

FIgURE 11: Indigo Carmine degradation profile of commercial $\mathrm{TiO}_{2}$ and $\mathrm{S} / \mathrm{Gd}^{3+}$-codoped $\mathrm{TiO}_{2}$ with different concentrations of $\mathrm{Gd}^{3+}$.

due to the dominance of the $\mathrm{d}-\mathrm{f}$ transitions over the $\mathrm{sp}-\mathrm{d}$ transitions.

3.6. Photocatalytic Activity. The visible-light activity of the asprepared nanoparticles was evaluated for the degradation of organic pollutants in aqueous solution, using Indigo Carmine (IC) dye as the model pollutant. The optical absorption peak at $610 \mathrm{~nm}$ was chosen to monitor the photodegradation process. The UV-visible spectral change of $20 \mathrm{ppm} \mathrm{IC} \mathrm{as} \mathrm{a}$ function of irradiation time during the course of degradation by $\mathrm{TiO}_{2}-\mathrm{S} / \mathrm{Gd}^{3+}\left(0.6 \% \mathrm{Gd}^{3+}\right)$ is shown in Figure 10 .
With time increasing from 0 to $50 \mathrm{~min}$, the characteristic absorption band at peaks of $610 \mathrm{~nm}$ decreased gradually, indicating that the IC was gradually photodegraded by the catalyst. The IC was completely removed from the solution after $50 \mathrm{~min}$. The percentage removal for commercial $\mathrm{TiO}_{2}, \mathrm{TiO}_{2}-\mathrm{S}$, and $\mathrm{S} / \mathrm{Gd}^{3+}$-codoped $\mathrm{TiO}_{2}$ with different $\mathrm{Gd}^{3+}$ contents is shown in Table 1. The linear relationship of $\ln C_{0} / \mathrm{C}$ versus time (Figure 11) shows that the photocatalytic degradation of IC follows the pseudo-first-order kinetics:

$$
\ln \frac{C_{0}}{C}=k t,
$$




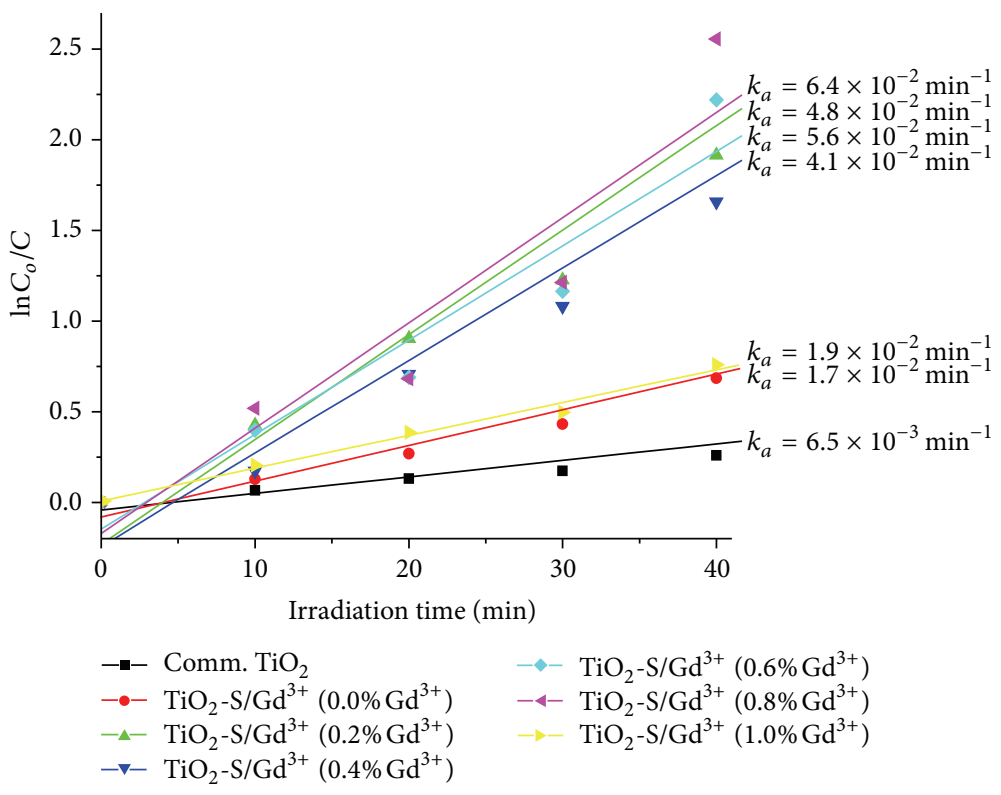

FIgURE 12: Kinetics of Indigo Carmine degradation in the first 40 min under visible light irradiation.

where $C_{0} / C$ is the normalized IC concentration, $t$ is the reaction time, and $k$ is the apparent reaction rate constant.

The value for $k$ (Table 1, Figure 12) for the $\mathrm{TiO}_{2}-\mathrm{S} / \mathrm{Gd}^{3+}$ $\left(0.6 \% \mathrm{Gd}^{3+}\right)$ (the most efficient photocatalyst) is $5.6 \times$ $10^{-2} \mathrm{~min}^{-1}$ which is about nine (9) times that of the commercial $\mathrm{TiO}_{2}, 6.5 \times 10^{-3} \mathrm{~min}^{-1}$, further demonstrating that the $\mathrm{S} / \mathrm{Gd}^{3+}$-codoped $\mathrm{TiO}_{2}$ exhibits high photocatalytic efficiency. The high photocatalytic performance of the codoped $\mathrm{TiO}_{2}$ could be assigned to a number of factors: (i) high visible-light absorption of the catalyst due to reduced band gap, (ii) the delayed electron-hole recombination due to trapping of electrons in the conduction band by $\mathrm{Gd}^{3+}$ orbital, (iii) efficient transfer of the charge carriers, and (iv) effective utilization of the charge carries by the reactants, as demonstrated by the UV-visible and UV-visible DRS analyses (Figures 6 and 7).

\section{Conclusions}

A series of $\mathrm{S} / \mathrm{Gd}^{3+}$-codoped $\mathrm{TiO}_{2}$ nanoparticles were synthesized by a modified sol-gel method. The samples were characterized by various spectroscopic and analytical techniques. XRD and Raman analysis confirm the formation of pure crystalline anatase phase $\mathrm{TiO}_{2}$. The UV-vis and UVvis DRS spectral analyses indicated that $\mathrm{S} / \mathrm{Gd}^{3+}$-codoping causes a red shift in the absorption band, resulting in the reduction in band gaps. The synergic effect of codoping with $\mathrm{S}$ and $\mathrm{Gd}^{3+}$ is evident in the photocatalytic performance of the catalyst. The $\mathrm{S} / \mathrm{Gd}^{3+}$ systems are very effective visible-light active photocatalysts for the degradation of Indigo Carmine. Highest photocatalytic activity was observed for the $\mathrm{TiO}_{2}$ $\mathrm{S} / \mathrm{Gd}^{3+}\left(0.6 \% \mathrm{Gd}^{3+}\right)$ sample. The enhanced photocatalytic activity was mainly attributed to the small crystallite size, intense light absorption in the visible region, and narrow band gap energy.

\section{Conflict of Interests}

The authors declare that they have no conflict of interests regarding the publication of this paper.

\section{Acknowledgments}

The authors gratefully acknowledge the financial support from the Faculty of Science, University of Johannesburg and the National Research Fund (NRF) South Africa, and Nanotechnology and Applications Centre, University of Allahabad, Allahabad, India. The authors also wish to thank Dr. H Mittal and Dr. V. Parashar, University of Johannesburg, for their technical support.

\section{References}

[1] R. N. Bhargava, D. Gallagher, X. Hong, and A. Nurmikko, "Optical properties of manganese-doped nanocrystals of $\mathrm{ZnS}$," Physical Review Letters, vol. 72, no. 3, pp. 416-419, 1994.

[2] T. Schmidt, G. Müller, L. Spanhel, K. Kerkel, and A. Forchel, "Activation of $1.54 \mu \mathrm{m} \mathrm{Er}^{3+}$ fluorescence in concentrated II-VI semiconductor cluster environments," Chemistry of Materials, vol. 10, no. 1, pp. 65-71, 1998.

[3] S. Sapra, A. Prakash, A. Ghangrekar, N. Periasamy, and D. D. Sarma, "Emission properties of manganese-doped $\mathrm{ZnS}$ nanocrystals," The Journal of Physical Chemistry B, vol. 109, no. 5, pp. 1663-1668, 2005.

[4] W. Chen, J.-O. Malm, V. Zwiller, R. Wallenberg, and J.-O. Bovin, "Size dependence of $\mathrm{Eu}^{2+}$ fluorescence in $\mathrm{ZnS}: \mathrm{Eu}^{2+}$ nanoparticles," Journal of Applied Physics, vol. 89, no. 5, pp. 2671-2675, 2001.

[5] M. A. Hines and P. Guyot-Sionnest, "Synthesis and characterization of strongly luminescing ZnS-capped CdSe nanocrystals," The Journal of Physical Chemistry, vol. 100, no. 2, pp. 468-471, 1996. 
[6] K. Rajeshwar, "Hydrogen generation at irradiated oxide semiconductor-solution interfaces," Journal of Applied Electrochemistry, vol. 37, no. 7, pp. 765-787, 2007.

[7] K. Rajeshwar and N. R. De Tacconi, "Solution combustion synthesis of oxide semiconductors for solar energy conversion and environmental remediation," Chemical Society Reviews, vol. 38, no. 7, pp. 1984-1998, 2009.

[8] X. Yang, F. Ma, K. Li et al., "Mixed phase titania nanocomposite codoped with metallic silver and vanadium oxide: New efficient photocatalyst for dye degradation," Journal of Hazardous Materials, vol. 175, no. 1-3, pp. 429-438, 2010.

[9] J. Zhao, C. Chen, and W. Ma, "Photocatalytic degradation of organic pollutants under visible light irradiation," Topics in Catalysis, vol. 35, no. 3, pp. 269-278, 2005.

[10] M. M. Mohamed and M. M. Al-Esaimi, "Characterization, adsorption and photocatalytic activity of vanadium-doped $\mathrm{TiO}_{2}$ and sulfated $\mathrm{TiO}_{2}$ (rutile) catalysts: degradation of methylene blue dye," Journal of Molecular Catalysis A, vol. 255, no. 1-2, pp. 53-61, 2006.

[11] S. Chakrabarti and B. K. Dutta, "Photocatalytic degradation of model textile dyes in wastewater using $\mathrm{ZnO}$ as semiconductor catalyst," Journal of Hazardous Materials, vol. 112, no. 3, pp. 269278, 2004.

[12] M. M. Joshi, N. K. Labhsetwar, P. A. Mangrulkar, S. N. Tijare, S. P. Kamble, and S. S. Rayalu, "Visible light induced photoreduction of methyl orange by N-doped mesoporous titania," Applied Catalysis A, vol. 357, no. 1, pp. 26-33, 2009.

[13] E. M. Rockafellow, L. K. Stewart, and W. S. Jenks, "Is sulfurdoped $\mathrm{TiO}_{2}$ an effective visible light photocatalyst for remediation?" Applied Catalysis B, vol. 91, no. 1-2, pp. 554-562, 2009.

[14] N. N. Binitha, Z. Yaakob, and R. Resmi, "Influence of synthesis methods on zirconium doped titania photocatalysts," Central European Journal of Chemistry, vol. 8, no. 1, pp. 182-187, 2010.

[15] J. M. Rehm, G. L. McLendon, Y. Nagasawa, K. Yoshihara, J. Moser, and M. Grätzel, "Femtosecond electron-transfer dynamics at a sensitizing dye-semiconductor $\left(\mathrm{TiO}_{2}\right)$ interface," The Journal of Physical Chemistry, vol. 100, no. 23, pp. 9577-9578, 1996.

[16] D. Chatterjee and S. Dasgupta, "Visible light induced photocatalytic degradation of organic pollutants," Journal of Photochemistry and Photobiology C, vol. 6, no. 2-3, pp. 186-205, 2005.

[17] J. E. Evans, K. W. Springer, and J. Z. Zhang, "Femtosecond studies of interparticle electron transfer in a coupled CdS- $\mathrm{TiO}_{2}$ colloidal system," The Journal of Chemical Physics, vol. 101, no. 7, pp. 6222-6225, 1994.

[18] L. Wu, J. C. Yu, and X. Fu, "Characterization and photocatalytic mechanism of nanosized CdS coupled $\mathrm{TiO}_{2}$ nanocrystals under visible light irradiation," Journal of Molecular Catalysis A, vol. 244, no. 1-2, pp. 25-32, 2006.

[19] W. Choi, A. Termin, and M. R. Hoffmann, "The role of metal ion dopants in quantum-sized $\mathrm{TiO}_{2}$ : correlation between photoreactivity and charge carrier recombination dynamics," The Journal of Physical Chemistry, vol. 98, no. 51, pp. 1366913679, 1994.

[20] R. Asahi, T. Morikawa, T. Ohwaki, K. Aoki, and Y. Taga, "Visible-light photocatalysis in nitrogen-doped titanium oxides," Science, vol. 293, no. 5528, pp. 269-271, 2001.

[21] T. Ohno, M. Akiyoshi, T. Umebayashi, K. Asai, T. Mitsui, and M. Matsumura, "Preparation of S-doped $\mathrm{TiO}_{2}$ photocatalysts and their photocatalytic activities under visible light," Applied Catalysis A, vol. 265, no. 1, pp. 115-121, 2004.
[22] Y. Cong, J. Zhang, F. Chen, and M. Anpo, "Synthesis and characterization of nitrogen-doped $\mathrm{TiO}_{2}$ nanophotocatalyst with high visible light activity," The Journal of Physical Chemistry C, vol. 111, no. 19, pp. 6976-6982, 2007.

[23] W. Ren, Z. Ai, F. Jia, L. Zhang, X. Fan, and Z. Zou, "Low temperature preparation and visible light photocatalytic activity of mesoporous carbon-doped crystalline $\mathrm{TiO}_{2}$," Applied Catalysis B, vol. 69, no. 3-4, pp. 138-144, 2007.

[24] H. Irie, Y. Watanabe, and K. Hashimoto, "Nitrogen-concentration dependence on photocatalytic activity of $\mathrm{TiO}_{2-x} \mathrm{~N}_{x}$ powders," The Journal of Physical Chemistry B, vol. 107, no. 23, pp. 5483-5486, 2003.

[25] T. H. Xu, C. L. Song, Y. Liu, and G. R. Han, "Band structures of $\mathrm{TiO}_{2}$ doped with $\mathrm{N}, \mathrm{C}$ and B," Journal of Zhejiang University Science B, vol. 7, no. 4, pp. 299-306, 2006.

[26] D. Li, H. Haneda, N. K. Labhsetwar, S. Hishita, and N. Ohashi, "Visible-light-driven photocatalysis on fluorine-doped $\mathrm{TiO}_{2}$ powders by the creation of surface oxygen vacancies," Chemical Physics Letters, vol. 401, no. 4-6, pp. 579-584, 2005.

[27] D. Li, H. Haneda, S. Hishita, N. Ohashi, and N. K. Labhsetwar, "Fluorine-doped $\mathrm{TiO}_{2}$ powders prepared by spray pyrolysis and their improved photocatalytic activity for decomposition of gasphase acetaldehyde," Journal of Fluorine Chemistry, vol. 126, no. 1, pp. 69-77, 2005.

[28] Y. Cui, H. Du, and L. Wen, "Origin of visible-light-induced photocatalytic properties of S-doped anatase $\mathrm{TiO}_{2}$ by firstprinciples investigation," Solid State Communications, vol. 149, no. 15-16, pp. 634-637, 2009.

[29] H. Sun, Y. Bai, Y. Cheng, W. Jin, and N. Xu, "Preparation and characterization of visible-light-driven carbon-sulfur-codoped $\mathrm{TiO}_{2}$ photocatalysts," Industrial and Engineering Chemistry Research, vol. 45, no. 14, pp. 4971-4976, 2006.

[30] K. Lv, H. Zuo, J. Sun et al., "(Bi, C and N) codoped $\mathrm{TiO}_{2}$ nanoparticles," Journal of Hazardous Materials, vol. 161, no. 1, pp. 396-401, 2009.

[31] H. Xu and L. Zhang, "Selective nonaqueous synthesis of CCl-codoped $\mathrm{TiO}_{2}$ with visible-light photocatalytic activity," The Journal of Physical Chemistry C, vol. 114, no. 26, pp. 11534-11541, 2010.

[32] Y. Cong, J. Zhang, F. Chen, M. Anpo, and D. He, "Preparation, photocatalytic activity, and mechanism of nano- $\mathrm{TiO}_{2} \mathrm{Co}$-doped with nitrogen and iron (III)," The Journal of Physical Chemistry C, vol. 111, no. 28, pp. 10618-10623, 2007.

[33] Y. Wang, Y. Huang, W. Ho, L. Zhang, Z. Zou, and S. Lee, "Biomolecule-controlled hydrothermal synthesis of C-N-Stridoped $\mathrm{TiO}_{2}$ nanocrystalline photocatalysts for $\mathrm{NO}$ removal under simulated solar light irradiation," Journal of Hazardous Materials, vol. 169, no. 1-3, pp. 77-87, 2009.

[34] P. Wang, P.-S. Yap, and T.-T. Lim, "C-N-S tridoped $\mathrm{TiO}_{2}$ for photocatalytic degradation of tetracycline under visible-light irradiation," Applied Catalysis A, vol. 399, no. 1-2, pp. 252-261, 2011.

[35] Y. Sakatani, H. Ando, K. Okusako et al., "Metal ion and N codoped $\mathrm{TiO}_{2}$ as a visible-light photocatalyst," Journal of Materials Research, vol. 19, no. 7, pp. 2100-2108, 2004.

[36] Y. Sakatani, J. Nunoshige, H. Ando et al., "Photocatalytic decomposition of acetaldehyde under visible light irradiation over $\mathrm{La}^{3+}$ and $\mathrm{N} \mathrm{Co-doped} \mathrm{TiO}_{2}$," Chemistry Letters, vol. 32, no. 12, pp. 1156-1157, 2003.

[37] W. Zhao, W. Ma, C. Chen, J. Zhao, and Z. Shuai, "Efficient degradation of toxic organic pollutants with $\mathrm{Ni}_{2} \mathrm{O}_{3} / \mathrm{TiO}_{2-x} \mathrm{~B}_{x}$ 
under visible irradiation," Journal of the American Chemical Society, vol. 126, no. 15, pp. 4782-4783, 2004.

[38] U. Siemon, D. Bahnemann, J. J. Testa, D. Rodríguez, M. I. Litter, and N. Bruno, "Heterogeneous photocatalytic reactions comparing $\mathrm{TiO}_{2}$ and $\mathrm{Pt} / \mathrm{TiO}_{2}$," Journal of Photochemistry and Photobiology A, vol. 148, no. 1-3, pp. 247-255, 2002.

[39] A.-W. Xu, Y. Gao, and H.-Q. Liu, "The preparation, characterization, and their photocatalytic activities of rare-earth-doped $\mathrm{TiO}_{2}$ nanoparticles," Journal of Catalysis, vol. 207, no. 2, pp. 151157, 2002.

[40] K. Wilke and H. D. Breuer, "The influence of transition metal doping on the physical and photocatalytic properties of titania," Journal of Photochemistry and Photobiology A, vol. 121, no. 1, pp. 49-53, 1999.

[41] F. B. Li, X. Z. Li, and M. F. Hou, "Photocatalytic degradation of 2-mercaptobenzothiazole in aqueous $\mathrm{La}^{3+}-\mathrm{TiO}_{2}$ suspension for odor control," Applied Catalysis B, vol. 48, no. 3, pp. 185-194, 2004.

[42] M. Zalas and M. Laniecki, "Photocatalytic hydrogen generation over lanthanides-doped titania," Solar Energy Materials and Solar Cells, vol. 89, no. 2-3, pp. 287-296, 2005.

[43] Y. Wang, H. Cheng, L. Zhang et al., "The preparation, characterization, photoelectrochemical and photocatalytic properties of lanthanide metal-ion-doped $\mathrm{TiO}_{2}$ nanoparticles," Journal of Molecular Catalysis A, vol. 151, no. 1-2, pp. 205-216, 2000.

[44] Y. Xie and C. Yuan, "Visible-light responsive cerium ion modified titania sol and nanocrystallites for X-3B dye photodegradation," Applied Catalysis B, vol. 46, no. 2, pp. 251-259, 2003.

[45] Y. Zhang, H. Xu, Y. Xu, H. Zhang, and Y. Wang, "The effect of lanthanide on the degradation of $\mathrm{RB}$ in nanocrystalline $\mathrm{Ln} / \mathrm{TiO}_{2}$ aqueous solution," Journal of Photochemistry and Photobiology A, vol. 170, no. 3, pp. 279-285, 2005.

[46] F. Boccuzzi, A. Chiorino, S. Tsubota, and M. Haruta, "FTIR study of carbon monoxide oxidation and scrambling at room temperature over gold supported on $\mathrm{ZnO}$ and $\mathrm{TiO}_{2}$," The Journal of Physical Chemistry, vol. 100, no. 9, pp. 3625-3631, 1996.

[47] P. Cheng, J. Qiu, M. Gu, Y. Jin, and W. Shangguan, "Synthesis of shape-controlled titania particles from a precursor solution containing urea," Materials Letters, vol. 58, no. 29, pp. 3751-3755, 2004.

[48] H. Sun, Y. Bai, Y. Cheng, W. Jin, and N. Xu, "Preparation and characterization of visible-light-driven carbon-Sulfur-codoped $\mathrm{TiO}_{2}$ photocatalysts," Industrial and Engineering Chemistry Research, vol. 45, no. 14, pp. 4971-4976, 2006.

[49] A. T. Kuvarega, R. W. M. Krause, and B. B. Mamba, "Nitrogen/palladium-codoped $\mathrm{TiO}_{2}$ for efficient visible light photocatalytic dye degradation," The Journal of Physical Chemistry C, vol. 115, no. 45, pp. 22110-22120, 2011.

[50] L. Ren, X. Huang, F. Sun, and X. He, "Preparation and characterization of doped $\mathrm{TiO}_{2}$ nanodandelion," Materials Letters, vol. 61, no. 2, pp. 427-431, 2007.

[51] J. A. Wang, R. Limas-Ballesteros, T. López et al., "Quantitative determination of titanium lattice defects and solid-state reaction mechanism in iron-doped $\mathrm{TiO}_{2}$ photocatalysts," The Journal of Physical Chemistry B, vol. 105, no. 40, pp. 9692-9698, 2001.

[52] H. C. Choi, Y. M. Jung, and S. B. Kim, "Size effects in the Raman spectra of $\mathrm{TiO}_{2}$ nanoparticles," Vibrational Spectroscopy, vol. 37, no. 1, pp. 33-38, 2005.
[53] D. B. Hamal and K. J. Klabunde, "Synthesis, characterization, and visible light activity of new nanoparticle photocatalysts based on silver, carbon, and sulfur-doped $\mathrm{TiO}_{2}$," Journal of Colloid and Interface Science, vol. 311, no. 2, pp. 514-522, 2007.

[54] M. Yan, F. Chen, J. Zhang, and M. Anpo, "Preparation of controllable crystalline titania and study on the photocatalytic properties," The Journal of Physical Chemistry B, vol. 109, no. 18, pp. 8673-8678, 2005.

[55] N. Venkatachalam, M. Palanichamy, and V. Murugesan, "Solgel preparation and characterization of alkaline earth metal doped nano $\mathrm{TiO}_{2}$ : efficient photocatalytic degradation of 4chlorophenol," Journal of Molecular Catalysis A, vol. 273, no. 1-2, pp. 177-185, 2007.

[56] S. Sakthivel and H. Kisch, "Daylight photocatalysis by carbonmodified titanium dioxide," Angewandte Chemie, vol. 42, no. 40, pp. 4908-4911, 2003. 

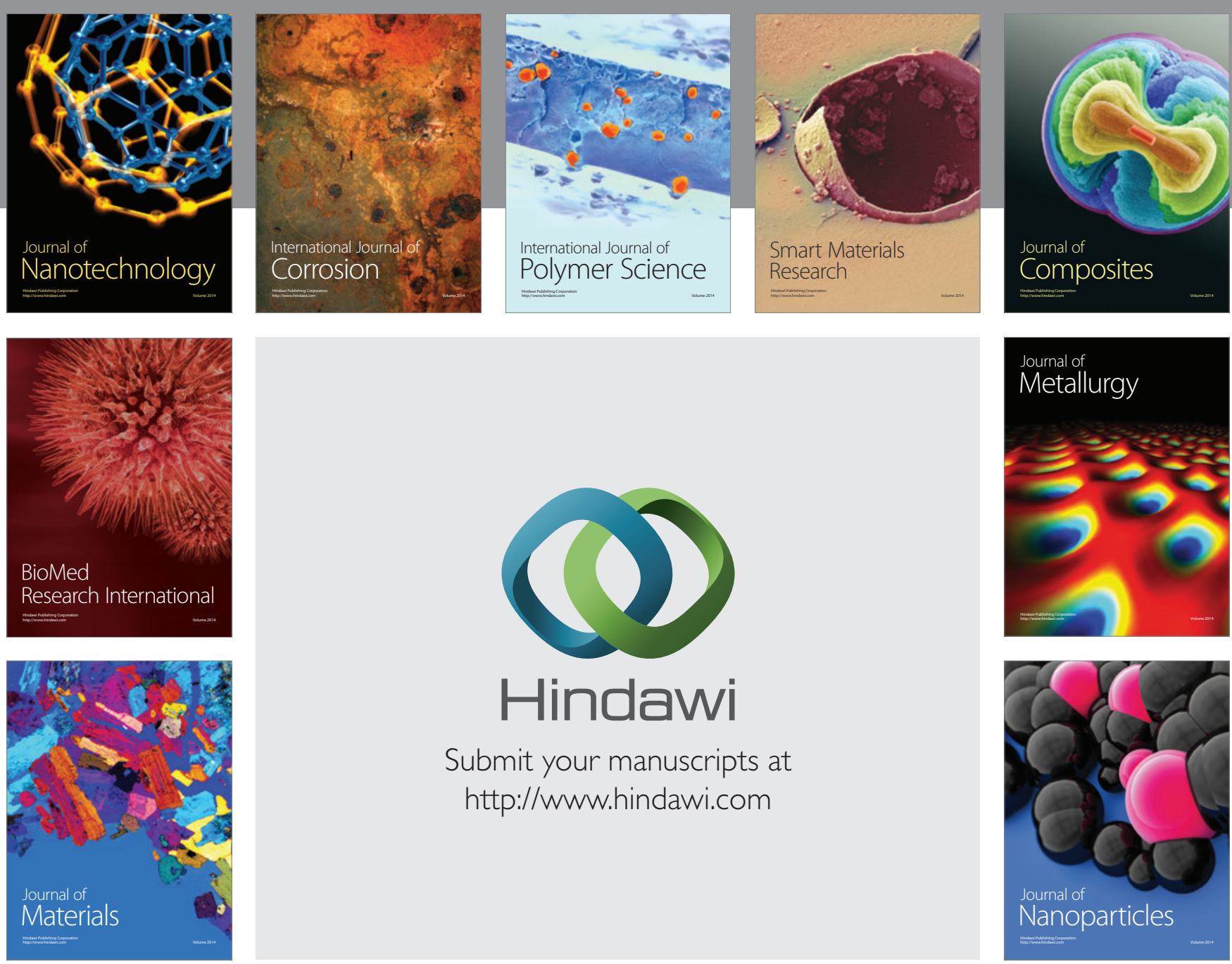

Submit your manuscripts at http://www.hindawi.com
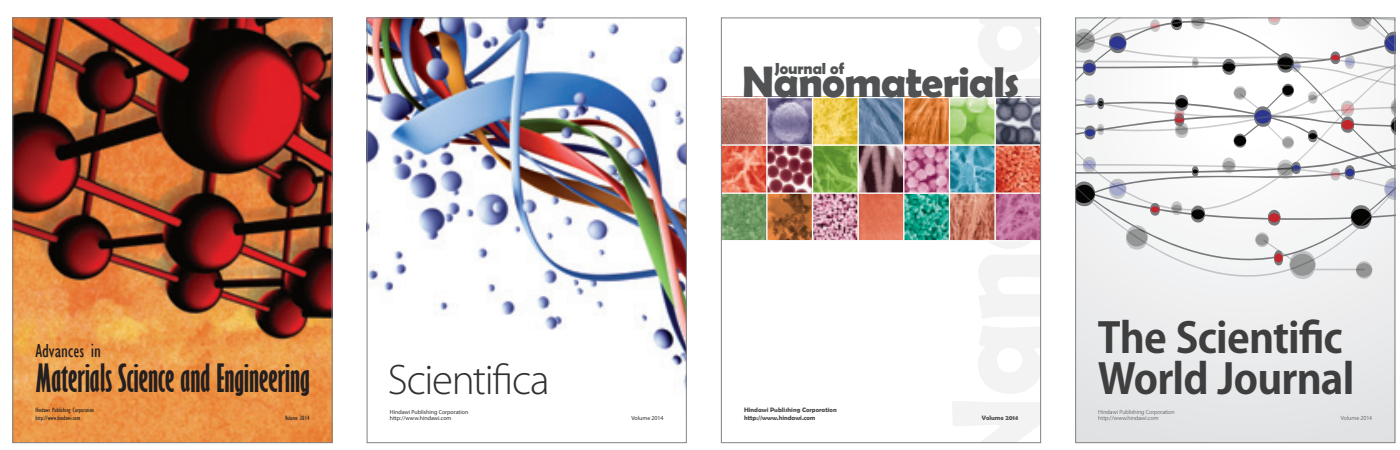

\section{The Scientific World Journal}
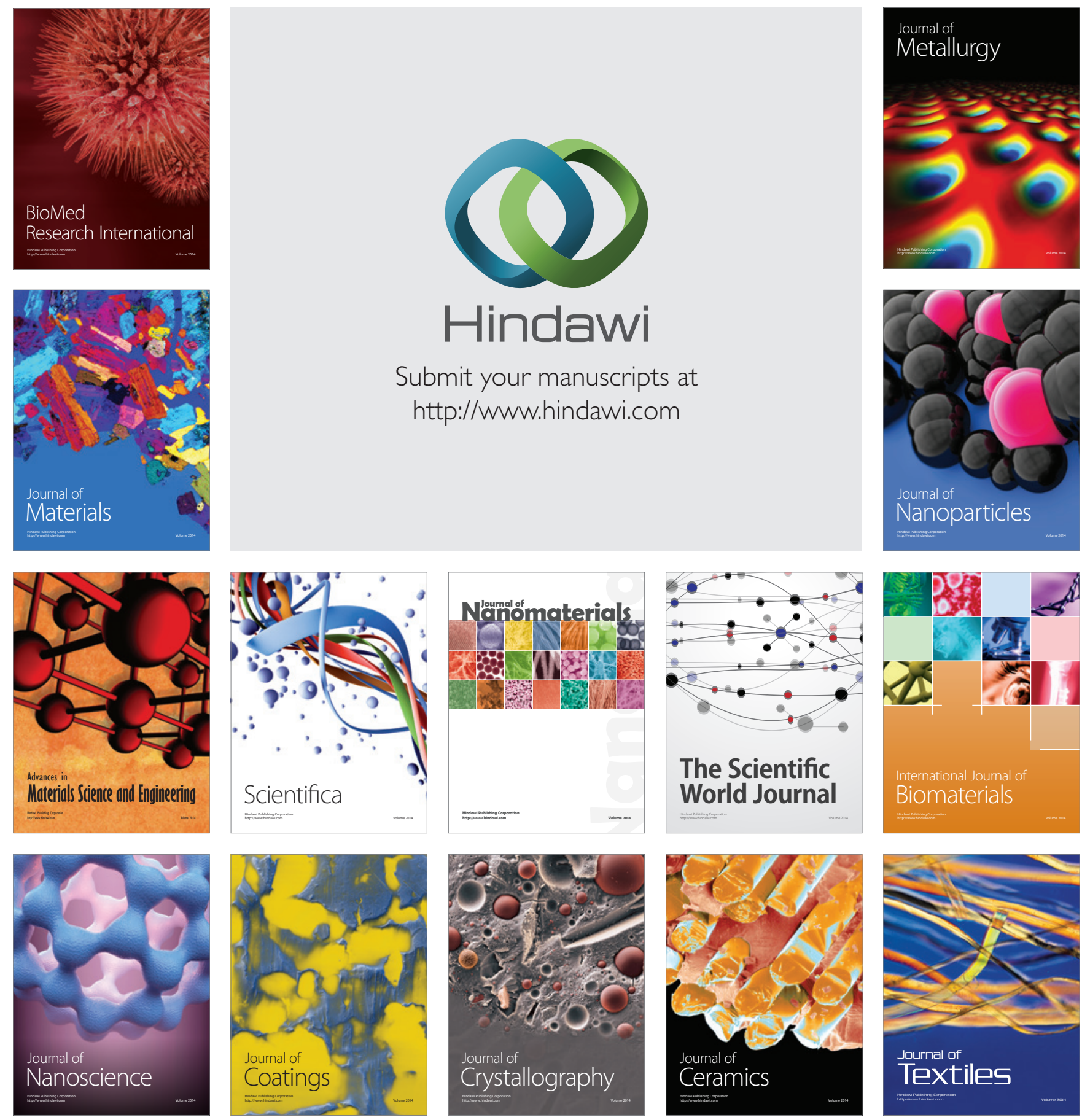